Aletria, Belo Horizonte, v. 30, n. 1, p. 173-187, 2020

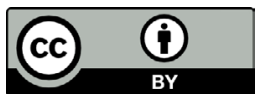

\title{
Caetano Veloso e a viravolta da cultura: dispositivos de leitura de Silviano Santiago
}

\section{Caetano Veloso and the Turn of Culture: Reading Devices by Silviano Santiago}

\author{
Roberto Alexandre do Carmo Said \\ Universidade Federal de Minas Gerais (UFMG), Belo Horizonte, Minas Gerais / Brasil \\ robertosaid@uol.com.br \\ http://orcid.org/0000-0002-6827-3852
}

Resumo: Pretendo analisar, neste artigo, o dispositivo de leitura engendrado por Silviano Santiago em sua investigação da viravolta cultural que reposiciona os estudos literários e as relações entre arte e política no final da década de 1970 no Brasil. Tomo como corpus três ensaios de Santiago, elaborados em diferentes momentos de sua trajetória intelectual, a partir dos quais busco identificar procedimentos críticos comuns que caracterizam um modo singular de aproximação do objeto, a um só tempo difuso e agudo, cuja recorrência revela uma obsessão do crítico pelas inflexões e pelos descentramentos na ordem da cultura. A ênfase recai na figura de Caetano Veloso e de sua atitude antropofágica cujo trabalho, em confluência com o de Santiago, conjuga elementos de diferentes registros culturais, de modo a revelar as ambiguidades e os paradoxos instituídos entre o campo estético e o político, entre a arte e a cultura, no processo de modernização conservadora da sociedade brasileira.

Palavras-chave: Caetano Veloso; entre-lugar; antropofagia; tropicalismo; indústria cultural.

Abstract: This article aims at analyzing the reading device created by Silviano Santiago in his investigation of the cultural turning point that repositioned literary studies and the relations between Art and Politics in the late 1970s in Brazil. This article elects three essays by Santiago, elaborated at different moments of his intellectual trajectory, from which I seek to identify common critical procedures that characterize a singular 
manner of approaching the object. Its recurrence reveals an obsession of the critic for the inflections and decentrations in the order of culture. The emphasis is on the figure of Caetano Veloso and his anthropophagic attitude. Velosos's work, in confluence with that of Santiago, combines elements of different cultural records, in order to reveal the ambiguities and paradoxes established between the aesthetic and the political field, between art and culture, in the process of conservative modernization of Brazilian society.

Keywords: Caetano Veloso; in-between; anthropophagy; tropicalism; cultural industry.

\section{Introdução}

A leitura crítica não pode renunciar a uma operação aparentemente simples: a busca de recorrências. Trata-se de identificar o que se repete no objeto da análise, com a premissa de que a repetição "faz sentido", isto é, de que ela produz significação. A repetição baliza a interpretação psicanalítica na virada do século XIX. Para Freud, a "terapia" é uma viagem ao fundo da repetição. Um pouco antes, Nietzsche formulava o conceito de eterno retorno ao tomar a repetição como algo novo, pois o que retorna não o faz como o idêntico. Décadas mais tarde, o estruturalismo buscava, sob a particularidade de produções individuais, os elementos recorrentes capazes de revelar a "gramática" de uma narrativa. A estrutura pressupunha um padrão de repetições. A repetição torna-se também dispositivo estético na arte moderna, e não apenas no domínio serial. A bricolage, a citação e a intertextualidade, bem como a atividade de todas as classes de artistas falsários e copistas colocam repetições em movimento. Diferença e repetição, dirá Gilles Deleuze, substituem o idêntico e o negativo. As repetições coexistem no espaço em que se distribui a diferença.

Parto, portanto, dessa operação básica de leitura. Busco identificar um gesto recorrente nas interpretações de Silviano Santiago, gesto já desencadeado em Uma literatura nos trópicos, sua primeira coletânea de ensaios, publicada em 1978. Entendo que sua extensa obra, não obstante a longevidade e a diversidade de interesses e dos gêneros literários e críticos em que se aplica, apresenta uma inquestionável coerência interna, alcançada, entre outras razões, pela repetição de um dispositivo de leitura. Santiago é sempre o mesmo sendo, no entanto, sempre outro. Procuro identificar e explorar, em seguida, alguns significados dessa repetição, atrelando-a a movimentos maiores de seu ensaísmo. 


\section{Passagens}

Tomo como epígrafe o trecho de uma entrevista de Silviano Santiago, publicada no livro de Adauto Novaes, Anos 70: literatura:

[...] daí a necessidade de estabelecer uma nova estratégia de leitura: minimizar toda a dívida (embora ela exista e seja forte) para com o estrangeiro, tentando maximizar (embora ela seja mínima) a contribuição original que, apesar dos pesares, é a marca da nossa inscrição na cultura.

Silviano Santiago ${ }^{1}$

Em um ensaio recente, elaborado sob encomenda no redemoinho de debates acerca dos impasses políticos pós-impeachment, Silviano Santiago (2017) retorna à década de 1970, a fim de empreender uma espécie de genealogia do best-seller literário em território brasileiro. Ao se valer do conceito de contemporâneo elaborado por Giorgio Agamben (2009) e da imagem da moda que o reveste alegoricamente, o crítico aponta o escritor mineiro Roberto Drummond como o nosso precursor na defesa de uma literatura voltada para o mercado e preocupada em oferecer uma espécie de amparo para o leitor. Conforme analisa Santiago, o autor de Hilda furação vislumbrava, ainda que não sem ambiguidades, outro destino para a literatura brasileira, desvinculando-a do empenho nacionalista ou da trilha da autonomia estética, traços que a caracterizaram desde pelo menos a emergência do modernismo. Já não se tratava, para R. Drummond, de buscar formas de representação das idiossincrasias e das contradições de nossa formação histórica, elaborados em arranjos intelectuais e estéticos, conforme fora consagrado pela tradição moderna, mas de priorizar a comunicação e de conceder a liberdade de recepção para um universo mais amplo de leitores. Idealizava, conforme citação de Santiago (2017, p. 233), "uma literatura que o menino aí do elevador, numa hora de folga, num feriado, possa pegar e ler e entender à maneira dele". Atento às luzes, mas não às trevas do tempo contemporâneo, ou

\footnotetext{
${ }^{1}$ Trata-se da entrevista concedida a Heloísa Buarque de Hollanda e a Marcos Augusto Gonçalvez, intitulada “A crítica literária na década de 1970” e inserida em Anos 70: literatura (1979), organizado por Adauto Novaes, e recompilada na coleção Encontros, Silviano Santiago (2001).
} 
melhor dizendo, "cego pelo excesso de luzes" do presente, o escritor mineiro se contrapunha à literatura alternativa ou underground produzida no período em que publica a sua coletânea de contos $A$ morte de $D$. $J$. em Paris (1971), ao sugerir um paradigma pop, sem no entanto defini-lo precisamente, a partir do qual a literatura pudesse se inserir na vida do cidadão comum, valendo-se de sua linguagem, proporcionando-lhe de volta o bem-estar equivalente ao de um relaxante cigarro ou o alívio de uma aspirina.

A proposta de uma literatura pop, jovem, "atualizada" e capaz de aliviar mazelas interiores, esboçada despretensiosamente em R. Drummond, receberia, segundo o crítico, versão definitiva e bemsucedida na década seguinte com a obra de Paulo Coelho. O mago e ex-parceiro de Raul Seixas converterá o ideal do amparo em autoajuda, o desbunde, que irrompe na cena cultural brasileira dos setenta, em nostalgia de tempos místicos, a linguagem coloquial em linguagem indiferenciada e acessível a todos, e, com essa fórmula, tal como o alquimista transforma metais ordinários em ouro, transformará o livro pop em best-seller, com um alcance internacional jamais alcançado por qualquer outro escritor brasileiro.

O olhar de Santiago cartografa, a partir das mutações em curso no âmbito literário nacional, a consolidação da sociedade de consumo cujo desenvolvimento histórico se dá paralelamente aos processos de distensão política e de reconquista democrática. Entre as formulações contraditórias de R. Drummond, cujos produtos literários não deixam de ser bem-sucedidos comercialmente, e o sucesso mundial de Paulo Coelho, modificam-se práticas, espaços e experiências de leitura, assim como o campo editorial, adaptados doravante às demandas sempre volúveis do mercado, de modo a anunciar "uma tendência que se amplificaria e se tornaria vitoriosa no plano da comunidade como um todo" (SANTIAGO, 2006, p. 239). ${ }^{2}$

Esse interesse genealógico pela cultura de massas e pelo consumo, tal como fora dirigido ao best-seller, já podia ser notado em um artigo de Santiago sobre Caetano Veloso, elaborado há mais de 40 anos e publicado

\footnotetext{
${ }^{2}$ Não deixa de ser curioso o fato de que o argumento apresentado por S. Santiago a respeito de R. Drummond se baseie na leitura de uma entrevista do escritor e não na leitura de sua obra literária, ao contrário do argumento apresentado acerca de Paulo Coelho.
} 
em Uma literatura nos trópicos. ${ }^{3}$ Nesse texto, a atenção do crítico não se dirige às canções do artista baiano, mas aos significados de sua postura performática deflagrada especialmente após o retorno do exílio político, com vistas a compreender as mutações da cena cultural brasileira.

Após a forçada, mas produtiva temporada londrina, durante a qual gravou dois álbuns, além de algumas canções de carnaval, Caetano retornaria ao Brasil em janeiro de 1972, e se apresentaria nos palcos das principais capitais brasileiras com a turnê Transa, exibindo-se com seu novo repertório (e novo visual) em diferentes programas de TV nos quais, pela primeira vez, apresentava-se publicamente tocando seu instrumento, reativando a estética do "banquinho e violão" consagrada com a Bossa Nova e que se tornaria doravante um traço característico também em sua carreira. No entanto, a leitura do Caetano pós-tropicalista empreendida por Santiago concentra-se antes na dimensão performática e comportamental do que na dimensão musical propriamente dita ou, melhor dizendo, interessa-se pelos elementos comportamentais que, inseridos na ambiência da curtição, da expansão do consumo cultural e da repressão do regime militar, agem dentro e fora da música. Caetano vira moda, Caetano dita a moda para os fãs, "desdobra-se em criador e criatura": "a jardineira que Caetano vestia ao chegar ao Galeão de repente prolifera-se pelos quatro cantos da cidade, como que reproduzida por mãos de fada" (SANTIAGO, 2006, p. 161). Causa igualmente espanto e estranheza, dividindo a opinião pública; divide-se ele mesmo entre os cadernos de cultura e as colunas sociais da imprensa brasileira.

O que está em jogo é a própria ideia de representação, visto que Caetano, na condição de "superastro", elimina as diferenças entre sua vida comum e a vida de astro pop. Não veste mais a máscara ou, talvez, já não a retire. Os espaços se embaralham, a ponto de tudo se tornar artifício: "levar a arte para o palco da vida. Levar a vida para a realidade do palco" (SANTIAGO, 2000. p. 149). Caetano evidencia que o mundo moderno, nas últimas décadas do século XX, não é mais o mundo da representação, mas o dos simulacros. As identidades não podem senão ser simuladas, produzidas, em um jogo profundo que é o da diferença e repetição. $\mathrm{O}$ verdadeiro sujeito da repetição é a própria máscara; ele não poder ser aprendido senão no movimento que faz de uma máscara a outra. O repetido não pode ser representado, observa Deleuze, "porque

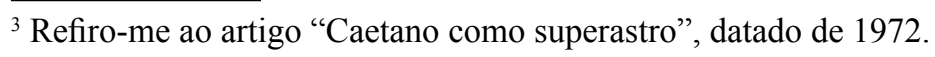


a repetição difere por natureza da representação, o repetido não pode ser representado, embora deva ser sempre significado em suas máscaras, colocando máscaras, por sua vez, naquilo que significa" (DELEUZE, 2002 , p. 45, tradução nossa). De acordo com Santiago, Caetano passa a se apresentar e a se representar sempre o mesmo, em casa e na rua, nos palcos e fora dele, de tal modo que nele se irmanam e se confundem uma "atitude artística diante da vida e uma atitude existencial de arte" (SANTIAGO, 2000, p. 150).

O cantor baiano demonstrava plena consciência do impacto da imagem do artista e de sua performance num cenário de expansão e popularização da TV e da mídia no Brasil. Sua ação se estende à esfera comportamental e seu corpo se torna a síntese "que serviria para definir o caos de um momento que não sendo mais de contestação pura, oferecese, no descompromisso e na ligeireza" (SANTIAGO, 2000, p. 158). Caetano, resume o crítico, "trouxe para o palco da praça e para a praça do palco o próprio corpo, e deu o primeiro passo para ser o superastro por excelência das artes brasileiras" (SANTIAGO, 2000, p. 158).

Uma terceira leitura de Santiago, também obcecada com a inquirição das passagens - exploro aqui a emblemática imagem benjaminiana - concentra-se no mesmo período histórico, isto é, nos famigerados anos de 1970, mas desta vez para analisar as "patrulhas ideológicas e a redemocratização política" em curso no final da década. Questiona-se o crítico na abertura de seu ensaio:

Quando é que a cultura brasileira despe as roupas negras e sombrias da resistência à ditadura militar e se veste com as roupas transparentes e festivas da democratização? Quando é que a arte brasileira deixa de ser literária e sociológica para ter uma dominante cultural e antropológica? Quando é que se rompem as muralhas da reflexão crítica que separavam, na modernidade, o erudito do popular e do pop? (SANTIAGO, 1998, p. 11).

Colocadas em contiguidade, as perguntas apontam a conexão entre as transformações políticas, artísticas e culturais e conduzem o crítico ao triênio 1979-1981, anos de anistia e de reabertura política, mas mais especificamente anos em que as publicações de jovens acadêmicos cariocas (Heloisa Buarque e Carlos Alberto Messeder), a respeito dos poetas marginais, fomentavam polêmicas que indiciariam a problemática 
emergência do paradigma cultural e, por ricochete, o fim da coesão das esquerdas no Brasil. ${ }^{4} \mathrm{O}$ événement "patrulhas ideológicas", expressão difundida pelo cineasta Cacá Diegues e que serviria de título para uma coletânea de entrevistas com artistas e escritores brasileiros, nomeava a censura promovida pela tradição do pensamento marxista cunhada sob a ideologia do desenvolvimentismo nacional-popular. Tratava-se da dicção e do entendimento políticos materializados no modelo do "Partidão" e de seus correlatos, que, não obstante sua face censora no âmbito da cultura e do comportamento, enfrentou com bravura a ditadura militar no Brasil e, de resto, na América Latina.

Santiago (1998, p. 13) comenta que o debate e as cisões em curso se dariam privilegiadamente no domínio da arte, considerando-se esta não mais como manifestação fundada na autonomia estética, "mas como fenômeno multicultural que estava servindo para criar novas e plurais identidades sociais". Coloca-se em suspensão a especificidade e a hegemonia do discurso literário e/ou artístico, em busca de sua comunicabilidade e de sua capacidade de mediação cultural, numa operação teórico-metodológica (e geracional) que, tal como uma dobra, expõe no campo literário as fraturas em curso na macroarena histórica. Novamente vem de Caetano Veloso (apud SILVIANO, 1998, p. 15), um dos entrevistados pelos jovens professores universitários, a síntese certeira: "o que mais incomoda [as pessoas] é a minha vontade de cotidianizar a política ou de politizar o cotidiano.” Em uma ambiência cultural dominada, no campo progressivo, pelo nacionalismo de esquerda, o cantor parece operar com o esgotamento de estéticas ideologicamente engajadas e dos discursos críticos fundados, seja nos preceitos das vanguardas, com a defesa da autonomia da arte, seja na vertente sociológica de orientação marxista. Na mirada de Santiago, Caetano simboliza a transformação do papel e do lugar do artista na sociedade, à medida que a cultura passa a ser encarada, não mais como um campo de simbolização acima ou anexo (dialeticamente) à sociedade, com o estudo das relações entre o texto artístico e o processo social que lhe dá origem,

4 Trata-se do artigo "Bandeiras da imaginação antropológica", resenha de Heloísa Buarque de Hollanda (RJ, Jornal do Brasil, 1981) acerca da obra Retratos de uma época: estudos sobre a poesia marginal na década de 70, de Carlos Alberto Messeder Pereira (1981) e ainda da coletânea de entrevista organizada pelos dois autores, intitulada Patrulhas ideológicas. 
tal como se explicita no clássico sintagma "literatura e sociedade", mas como um modo de vida.

A querela literária em torno dos marginais anunciaria a contestada viravolta cultural, fornecendo a cifra dos imbróglios estéticos e dos conflitos políticos que atuarão latentes até a queda definitiva do regime militar e, décadas mais tarde, serão ressuscitados, no campo dos estudos literários, nos calorosos debates atrelados à disseminação dos estudos culturais nas faculdades de Letras país afora. Caetano e o desbunde dos poetas marginais nos anos de 1970 quebram certezas autoproclamadas e colocam em pauta a reflexão concernente ao saber-não-saber da experiência, criando para o crítico zonas intersticiais de exploração.

\section{Só a antropofagia nos une?}

Tomados em conjunto, os três ensaios de Silviano Santiago, elaborados em décadas diferentes e sumariamente resenhados aqui, atestam a existência de uma espécie de agenciamento do olhar, um modo singular de aproximação do objeto, a um só tempo difuso e agudo, cuja recorrência revela uma obsessão do crítico pelas inflexões e descentramentos na ordem da cultura. Trata-se de um dispositivo de leitura fundado primeiramente na lógica do entre-lugar, noção original formulada pelo crítico no âmbito dos debates acerca da dependência cultural e do comparatismo literário e que, não sendo a rigor um conceito, poderia ser tomado como o operador de seu pensamento teórico e analítico. Da virada da década de 1960, quando apareceu em um artigo publicado em inglês (the space in-between), até os estudos recentes, camadas de significação e uma série de derivações, das quais as mais notórias seriam as ideias de "anfíbio" e "cosmopolitismo do pobre", acumularam-se sobre o "entre-lugar", de modo a revigorar sua potência analítica para ler associadamente as tramas do mundo-da-cultura e do mundo-da-política, da perspectiva das margens da modernidade.

O entre-lugar, como um tropo analítico (orientação teórico-política e lugar de enunciação) na cena cultural brasileira, contrapõe-se tanto às leituras balizadas no binarismo metrópole/colônia quanto à homologia estrutural entre a realidade e as obras artísticas, que fundamentam as leituras sociológicas tributárias do materialismo dialético e constituem a base da tradição hegemônica da crítica literária no Brasil. Distante da noção de dualidade tanto quanto da de síntese, fora do círculo 
hermenêutico da "formação" a partir do qual Antonio Candido identifica o "caráter interessado da literatura brasileira", o ensaísta de Nas malhas da letra visa analisar os espaços intersticiais e o encadeamento paradoxal que caracteriza, no caso em questão, aqueles espaços engendrados entre o livro pop e o best-seller ou entre o corpo do desbunde e o consumo de suas vestes e adereços, entre a diferença identitária e sua estetização mercantil, entre a biopolítica e o culto da personalidade.

Roberto Drummond, o primeiro escritor brasileiro a se imaginar pop, Paulo Coelho, exitoso vendedor de barateadas experiências espirituais-literárias, e Caetano Veloso, o primeiro superastro da música popular, cada qual a seu modo tornam-se, a partir da mirada crítica que lhes é lançada, signos de uma complexa alteração no domínio da cultura em que se enfeixam, assimetricamente, literatura e canção; estética, comportamento e consumo; experimentação e banalidade; máscara e espetáculo; o pop e o popular - sem perder de vista, certamente, a enorme distância que separa a postura, a visão crítica e os resultados alcançados pelos personagens em cena. Posto que há diferenças decisivas entre incorporar criticamente na fatura artística as condições de produção advindas da cultura de massas, na esteira da tradição baudelairiana, e produzir com a finalidade de atender as demandas impostas por tais condições. Enquanto R. Drummond se encanta com as possibilidades e, sobretudo, com as facilidades para expandir seu universo de leitores, e P. Coelho encontra a fórmula para realizar essas pretensões, ao mesclar em suas narrativas retalhos de sabedoria oriental, religiosidade e contracultura, oferecendo a "todos os homens" um "caminho" para que possam realizar sua "lenda pessoal", formulando máximas tais como "Onde você desejar ver a face de Deus, você verá" ou "O homem nunca pode parar de sonhar", ${ }^{5}$ Caetano busca equacionar o dilema que a cultura popular-massiva impunha à "liberdade inventiva", a fim de atualizar criativamente montagens artísticas exitosas na história da canção popular brasileira, tal como a que Orlando Silva havia logrado nos anos de 1930 ou como a de João Gilberto nos anos de 1950, conforme se lê na análise formulada em Verdade tropical:

${ }^{5}$ Frase e expressões de Diário de um mago e O Alquimista, de Paulo Coelho, indicadas por Eloésio Paulo em Dez pecados de Paulo Coelho (2014). 
[...] a circunstância de Orlando Silva ter sido ao mesmo tempo um fenômeno de massas e um artista de maior refinamento, fazia dele um ponto central de reflexão para quem queria enfrentar a questão da arte de massas e manter-se à altura da bossa nova. (VELOSO, 1999, p. 265).

[...] sua compreensão [a de João Gilberto] da modernidade instaura uma liberdade inventiva que transcende todas as questões de dependência cultural. (VELOSO, 1999, p. 267).

Santiago divide com Caetano Veloso, no decênio de 1970, o interesse herético pela cultura popular e pela cultura de massas, em suma, por tudo o que se reúne sob a rubrica da indústria cultural, como desdobramento de seu gesto crítico de deslocar tanto a condição do sujeito colonial frente à tradição metropolitana universalista quanto a de sujeitos excluídos das formações nacionais modernas na América Latina. Apontam, ambos, para a

continuidade entre discursos ou práticas coloniais, o autoritarismo e a tradição crítico-avaliativa que recusa o valor do Outro, seja do híbrido que emerge, como diferença, no embate colonial, seja do que se constitui no exterior do círculo privilegiado da cultura letrada e erudita. (CUNHA, 2008, p. 10).

A dessacralização das ideias de unidade e pureza, professada em Uma literatura nos trópicos, irmana-se com o gosto pelo entrecruzamento de diferentes registros da cultura e, por conseguinte, com o enfrentamento dos discursos críticos que, provenientes de diferentes matrizes ideológicas, insistem na "grande divisão" que separa categoricamente arte erudita e cultura de massas. ${ }^{6}$ Compartilham, cantor e crítico, embora muitas vezes apenas tangencialmente, de uma "razão antropofágica", para valer-me do termo de Haroldo de Campos (2006).

Caetano, como uma espécie de encarnação do "bárbaro tecnizado," capaz de reunir o cancioneiro e as tradições do recôncavo baiano com guitarras e performances do rock inglês, toma a antropofagia não apenas em sua interface externa, a partir da qual poderia ressignificar

\footnotetext{
${ }^{6}$ Em "O começo do fim", Silviano Santiago recorre à expressão "grande divisão" do historiador da arte Andreas Huyssen.
} 
a dependência cultural, mas também em sua eficácia interna, a fim de atravessar e mesclar os estratos culturais da formação social brasileira resultante de um processo de modernização conservadora. Perspectiva que lhe permite apontar João Gilberto como "um exemplo claro de atitude antropofágica", e considerar a poesia de Oswald como uma decisão de rigor para "resolver o problema de identidade no Brasil" e não uma panaceia ou um inconsequente coquetel de referências como postularam seus críticos.

Santiago, por sua vez, vale-se também da antropofagia, mas repensada à luz da desconstrução derridiana, para subverter no campo da cultura os valores entre original e cópia, afirmando nos anos de 1970 a diferença e a originalidade transgressora e subalterna dos trópicos "escrever é escrever contra" - bem como para a abertura e reconhecimento da alteridade, no âmbito dos debates pós-coloniais já no novo milênio. A esse respeito, vale notar que, ao longo de sua longeva trajetória intelectual, Santiago mantém praticamente inalterada sua apreciação da antropofagia, ao contrário de alguns pensadores e artistas de sua geração. Se é conhecido seu apreço pelo conceito oswaldiano, como se pode ler em seu livro de estreia como ensaísta, textos mais recentes reafirmam a primeira avaliação e passam a associar a antropofagia às noções de "má memória", "tolerância racial" ou ainda "rigor construtivista", este último entendido com o imperativo para o escritor brasileiro que precisa conjugar trabalho artístico e trabalho crítico. ${ }^{7}$

O compositor da tropicália e o autor do conto "O banquete" lançam mão da deglutição antropofágica como meio de ressignificação de relações políticas e culturais: "Nem alta cultura nem cultura de massa, a Antropofagia - ou a má memória - aponta para as duas, ao mesmo tempo" (SANTIAGO, 2008, p. 23). De um lado, a antropofagia cria modos de representação alternativos ao domínio colonial; de outro, abre-se sob a luz da desconstrução e do debate pós-colonial à experiência da diferença e da alteridade identitária e artística brasileira.

Caetano reparte o campo do sensível na arte brasileira ao trazer para o seu palco, para o seu corpo, suas roupas e suas canções restos de culturas populares obliteradas, fragmentos da cultura de massa que eram vistos com reserva, quando não com vergonha pelo público

\footnotetext{
7 Refiro-me especificamente aos textos de Santiago: "O começo do fim” (2008) e "Oswald de Andrade: ou o elogio da tolerância racial" (2006).
} 
médio. Os arranjos de R. Drummond e P. Coelho, por seu turno, não atravessam os estratos da cultura; ao contrário, dão ênfase e criam uma harmonia intrínseca com os elementos da cultura de massa, sem gerar dissonâncias entre os registros utilizados, pois buscavam uma audiência ampliada - como é também o caso de Roberto Carlos, comparado com o superastro por Silviano Santiago. ${ }^{8}$ Como o "rei", os dois escritores pop não se valem, para recorrer ao léxico pós-estruturalista mobilizado no pensamento do ensaísta, de uma montagem informada pela imaginação do paradoxo, capaz de uma representação crítica das contradições presentes na modernidade cultural brasileira. Já o superastro "é o significante em que os olhares se encontram para a metamorfose carnavalesca. Difícil é definir então o conteúdo deste significante, pois o significado é vário, distinto, polissêmico" (SANTIAGO, 2000, p. 149).

A esse respeito, não deixa de ser significativo que Caetano exporia, anos mais tarde, em Verdade Tropical, uma visão convergente à do crítico de Vale quanto pesa, ao refletir sobre a imagem-clichê consagrada por Carmem Miranda e devidamente reapropriada com a tropicália:

[...] a decretação da morte dessa vergonha pela aceitação desafiadora tanto da cultura de massas americana (portanto da Hollywood onde Carmem brilhara) quanto da imagem estereotipada de um Brasil sexualmente exposto, hipercolorido e frutal (que era a versão que Carmen levava ao extremo - aceitação que se dava por termos descoberto que tanto a mass culture quanto esse estereótipo eram (ou podiam ser) reveladores de verdades mais abrangentes sobre cultura e sobre Brasil do que aquelas a que estivéramos até então limitados. (VELOSO, 1999, p. 258).

\footnotetext{
${ }^{8}$ Anota Silviano Santiago (2000, p. 159): "O corpo é tão importante quanto a voz; a roupa é tão importante quanto a letra; o movimento é tão importante quanto a música. O corpo está para a voz, assim como a roupa está para a letra e a dança para a música. Deixar que os seis elementos desta equação não trabalhem em harmonia (o que sucede muitas vezes em Roberto Carlos), mas que se contradigam em toda sua extensão, de tal modo que se cria um estranho clima lúdico, permutacional, como se o cantor no palco fosse um quebra-cabeça que só pudesse ser organizado na cabeça dos espectadores."
} 
Considerados em grupo, os três ensaios em pauta, produzidos em diferentes contextos, mas todos eles voltados para o decênio de 1970, ao estabelecerem novos modos de aproximação do objeto investigado, abordam debates relativos às passagens entre o estético e o político, entre a arte e a cultura. A frase de Santiago (1998, p. 14), inserida em "Caetano Superastro", parece resumir a questão: "A política é a cultura rebelde de cada dia cujo perfume privado exala no espaço público." Nesse movimento de leitura que entrecruza o entre-lugar com a antropofagia, devidamente filtrados pela noção de diferença de Jacques Derrida, arte e política se imbricam no objeto cultural, a avaliação estética não se confunde com autonomia da arte nem tampouco omite as ambivalências dos projetos de vanguarda, além disso, interessa à crítica debater o posicionamento do artista e do intelectual brasileiro frente ao poder e ao Estado, bem como nos estratos populares-massivos.

É exatamente esse o dispositivo acionado para a inquirição de um incerto, mas significativo decurso da história cultural brasileira. Pois ao antecipar e inventariar o fim de século no Brasil, à maneira de Eric Hobsbawn e o seu breve século XX, Santiago - está claro - não descobre ou identifica a metamorfose ou os pontos de virada da cultura brasileira contemporânea, como se jogasse luzes sobre um mundo preexistente e com ele desvelasse um novo modelo de verdade. Os personagens e os eventos analisados não são naturalmente marcos ou monumentos históricos e culturais, são, antes, fabulados na leitura crítica, são criados em um diagrama que, ao contemplar formações discursivas e não discursivas, o visível e o enunciável, formas, afetos e poderes, tornase extensivo a todo o campo cultural. O ensaísta se vale da premissa derridiana segundo a qual o processo de determinação de sentido de um acontecimento é sempre dado a posteriori, através de práticas discursivas.

Os objetos e sujeitos estudados permitem a Santiago discutir a reconfiguração de valores em curso na história cultural e literária brasileira. E este é um aspecto caro ao pensamento do crítico, para quem a produção de sentido e a historicidade estão diretamente associadas à discussão do valor dos valores. A importância dos valores não decorre do fato de eles estabelecerem parâmetros de análise, como se existissem desde sempre, mas ao fato de que, em conformidade com o arqueamento nietzschiano, "os valores supõem avaliações, que lhes dão origem e conferem valor; estas, por sua vez, ao criá-los, supõem valores a partir dos quais avaliam" (SCARLETT, 2010, p. 87). Os dois movimentos são 
inseparáveis e permitem revisar os limites das categorias correntes, dentro das quais se organizava a historiografia artística e literária brasileira. Trata-se de um corte epistemológico a partir do qual a questão não é simplesmente de interpretar os textos a partir dos fundamentos escolhidos, seja sob viés hermenêutico, seja sob viés estético, seja em nome de uma pedagogia modernista do nacional, mas de colocar em circulação no gesto de leitura os pesos e as medidas a partir dos quais esses textos foram até então interpretados. Caetano Veloso é objeto privilegiado de análise à medida que seu falso teatro e sua inclinação antropofágica colocam em jogo novos pesos e medidas; sua trajetória demanda e propõe, não sem destilar seu hoje já conhecido gosto pela polêmica, novos instrumentos de aferição, ao propor um outro "comum" a sua comunidade, promovendo uma forma dissensual de partilha. ${ }^{9}$

A estratégia de leitura colocada em movimento desde a primeira hora por Silviano Santiago, em sua genealogia da cultura brasileira no "fim" do século XX, mais especificamente, da passagem da crítica literária à crítica cultural, da arte à cultura, dá visibilidade aos interstícios e aos paradoxos que conformam as relações entre o campo político e o estético nas margens tropicais do capitalismo.

\section{Referências}

AGAMBEN, Giorgio. O que é o contemporâneo? e outros ensaios. Chapecó: Argos, 2009.

CAMPOS, Haroldo de. Da razão antropofágica: diálogo e diferença na cultura brasileira. In: Metalinguagem e outras metas. São Paulo: Perspectiva, 2006. p. 231-256.

COELHO, Frederico (org.). Silviano Santiago. Rio de Janeiro: Beco do Azougue, 2001. (Coleção Encontros).

CUNHA, Eneida Leal (org.). Leituras crítica de Silviano Santiago. Belo Horizonte/São Paulo: Editora UFMG: Fundação Perseu Abramo, 2008.

\footnotetext{
${ }^{9}$ Vale notar, a esse respeito, a diferença de abordagem de Roberto Schwarz em suas análises da obra de Caetano Veloso e o debate com o compositor daí resultante, formulados nos textos "Cultura e política, 1964-1969" e "Verdade tropical: um percurso de nosso tempo" (2012).
} 
DELEUZE, Gilles. Diferencia y repetición. Buenos Aires: Amorrortu, 2002.

PAULO, Eloésio. Dez pecados de Paulo Coelho. Sabará: Dubolso Digital, 2014.

SANTIAGO, Silviano. Democratização no Brasil 1979-1981 (cultura versus arte). In: ANTELO, Raul (org.). Declínio da arte, ascensão da cultura. Florianópolis: Abralic, 1998. p. 11-24.

SANTIAGO, Silviano. A moda como metáfora contemporâneo. In: BOTELHO, André; STARLING, Heloísa. República e democracia: impasses do Brasil contemporâneo. Belo Horizonte, Ed. UFMG, 2017. p. 225-246

SANTIAGO, Silviano. O começo do fim. Gragoatá, Niterói, n. 24, p. 13-30, 1. sem. 2008.

SANTIAGO, Silviano. O cosmopolitismo do pobre. In:

O cosmopolitismo do pobre. crítica literária e crítica cultural. Bèlo Horizonte: Editora UFMG, 2004. p. 45-73.

SANTIAGO, Silviano. Ora (direis) puxar conversa!. Belo Horizonte: Editora UFMG, 2006. p. 209-214.

SANTIAGO, Silviano. Para além da história social. In: . Nas malhas da letra. Rio de Janeiro: Rocco, 2002. p. 251-271.

SANTIAGO, Silviano. Uma literatura nos trópicos. Rio de Janeiro: Rocco, 2000.

SCARLLET, Marton. Nietzsche: das forças cósmicas aos valores humanos. Belo Horizonte: Editora UFMG, 2010.

SCHWARZ, Roberto. Verdade tropical: um percurso de nosso tempo. In: . Martinha versus Lucrécia. São Paulo: Companhia das Letras, 2012. p. 155-356.

VELOSO, Caetano. Verdade tropical. São Paulo: Companhia das Letras, 1999.

Recebido em: $1^{\circ}$ de outubro de 2019. Aprovado em: 17 de dezembro de 2019. 